ISSN: 1858-4837;E-ISSN: 2598-019X

Volume 16, Nomor 1 (2021)

https://jurnal.uns.ac.id/region

DOI: 10.20961/region.v16i1.35205

\title{
Prioritas lokasi pendaftaran tanah sistematik lengkap dengan metode analisis hierarki proses dan overlay tertimbang di Kabupaten Semarang
}

\author{
Location priority for complete systematic land registration by analytical \\ hierarchy process and weighted overlay method in Semarang District
}

\author{
T C Yuda ${ }^{1}$, I Rudiarto ${ }^{2}$ \\ ${ }^{1}$ Magister Perencanaan Wilayah dan Kota, Fakultas Teknik, Universitas Diponegoro \\ 2 Departemen Perencanaan Wilayah dan Kota, Fakultas Teknik, Universitas \\ Diponegoro
}

Corresponding author's email: 7illuminazione@gmail.com

\begin{abstract}
Abstrak. Sesuai dengan rencana tata ruang wilayah Kabupaten Semarang, Kecamatan Sumowono dikembangkan menjadi kawasan pertanian produktif, dengan sistem agropolitan. Penataan ruang dapat dilakukan dengan optimal apabila seluruh bidang tanah pada kawasan tersebut sudah terdaftar, sehingga perencanaan, pemanfaatan dan pengendaliannya dapat dilakukan dengan seksama. Tujuan dari penelitian ini adalah menentukan prioritas lokasi pendaftaran tanah sistematik lengkap (PTSL) di Kecamatan Sumowono yang terdiri dari 16 desa. Metode yang digunakan adalah gabungan dari metode Analysis Hierarchy Process (AHP) dan Weighted Overlay. AHP digunakan untuk menentukan bobot setiap variabel penentuan prioritas, sedangkan analisis weighted overlay digunakan untuk menentukan prioritas lokasi PTSL dengan mengintegrasikan bobot dengan nilai masing-masing variabel di setiap desa. Hasil AHP menyatakan bahwa bobot tertinggi dalam perencanaan pendaftaran tanah sistematik lengkap adalah jumlah bidang tanah belum terdaftar $(30,3 \%)$ dan jumlah penduduk bekerja $(13,4 \%)$. Analisis terakhir menghasilkan tiga tingkat prioritas. Prioritas pertama terdapat pada Desa Candigaron. Prioritas kedua terdiri dari 9 desa: Desa Keseneg, Desa Pledokan, Desa Kemitir, Desa Losari, Desa Sumowono, Desa Jubelan, Desa Lanjan, Desa Ngadikerso, dan Desa Kebonagung. Sedangkan prioritas ketiga terdiri dari 6 desa: Desa Medongan, Desa Kemawi, Desa Piyanggang, Desa Bumen, Desa Trayu, dan Desa Duren.
\end{abstract}

Kata Kunci: Analisis Hierarkhi Proses (AHP), Prioritas Lokasi PTSL, Weighted Overlay

Received : October 28, 2019; Accepted: January 23, 2019; Available online: January 30, 2021

Copy right @ 2021, REGION: Jurnal Pembangunan Wilay ah dan Perencanaan Partisipatif 
Abstract. In accordance with the spatial plan of Semarang District, Sumowono SubDistrict was developed into a productive agricultural area, with an agropolitan system. Spatial planning can be optimized if the entire plot in the region are already registered, so that planning, utilization, and control can be done carefully. The purpose of this study is to determine the priority location of a Complete Systematic Land Registration (CSLR) in Sumowono Sub-District which consists of 16 villages. The method used is a combination of the Analysis Hierarchy Process (AHP) and Weighted Overlay methods. AHP is used to determine the weight of each priority setting variable, while the weighted overlay analysis is used to determine the priority of the CSLR location by integrating the weights with the values of each variable in each village. The AHP results state that the highest weight in a complete systematic land registration plan is the number of unregistered land parcels $(30.3 \%)$ and the number of working residents (13.4\%). The final analysis yields three priority levels. The first priority is in Candigaron village. The second priority consists of 9 villages: Keseneg Village, Pledokan Village, Kemitir Village, Losari Village, Sumowono Village, Jubelan Village, Lanjan Village, Ngadikerso Village, and Kebonagung Village. Whereas the third priority consists of 6 villages: Medongan Village, Kemawi Village, Piyanggang Village, Bumen Village, Trayu Village, and Duren Village.

Keywords: Analytical Hierarchy Process (AHP), CSLR Location Priority, Weighted Overlay

\section{Pendahuluan}

Sistem administrasi lahan adalah tentang bagaimana mengatasi permasalahan lahan dengan menyediakan infrastruktur dasar untuk menerapkan kebijakan terkait lahan dan strategi pengelolaannya untuk memastikan kesetaraan sosial, pertumbuhan ekonomi dan perlindungan lingkungan. Suatu sistem dapat melibatkan kerangka kerja konseptual modern yang didukung oleh model-model teknologi informasi dan komunikasi (TIK) seperti di banyak negara maju; atau mungkin melalui pendekatan yang sangat terfragmentasi yang ditemukan di negara-negara kurang berkembang [1].

Enemark [2] mengemukakan bahwa landasan teori administrasi lahan modern adalah paradigma tentang pengelolaan lahan di mana penguasaan lahan, nilai, penggunaan dan pengembangan dianggap secara holistik sebagai fungsi esensial dan yang ada di mana-mana yang dilakukan oleh masyarakat secara terorganisir. Dalam paradigma ini, setiap negara memberikan sasaran kebijakan pertanahannya dengan menggunakan berbagai teknik dan alat untuk mengelola lahan dan sumber dayanya. Apa yang didefinisikan sebagai administrasi lahan dalam teknik-teknik dan alat-alat manajemen ini adalah spesifik untuk setiap aturan hukum yang berlaku.

Pengelolaan lahan lebih luas daripada administrasi pertanahan. Ini mencakup semua kegiatan yang terkait dengan pengelolaan tanah dan sumber daya alam yang diperlukan untuk memenuhi tujuan politik dan mencapai pembangunan berkelanjutan. Pengelolaan lahan membutuhkan keterampilan antar-disiplin yang mencakup ilmu teknis, alam, dan 
sosial. Ini tentang kebijakan pertanahan, hak tanah, properti, ekonomi, kontrol penggunaan lahan, regulasi, pemantauan, implementasi, dan pengembangan [1].

Untuk mengimplementasikan kebijakan pengelolaan dengan baik diperlukan jaminan kepastian hukum atas kepemilikan lahan. Kekuatan status tanah tergantung pada aspek hukum dan sosial seseorang terkait dengan pemanfaatan lahan. Pada prinsipnya aspek hukum berisi pengakuan hukum kepemilikan tanah, sementara aspek sosial mensyaratkan realitas yang menghasilkan pengakuan masyarakat atas kepemilikan tanah. Kedua aspek tersebut dapat memperkuat posisi kepemilikan tanah, sehingga jaminan kepastian hukum menjadi sangat penting dalam perencanaan dan pengembangan lahan [3].

Jaminan kepastian hukum seseorang dalam kepemilikan lahan dibuktikan dengan sertifikat yang diterbitkan oleh lembaga pemerintah yaitu Kementerian Agraria dan Tata Ruang/ Badan Pertanahan Nasional. Dilihat dari jumlah lahan terdaftarnya, Kecamatan Sumowono memiliki jumlah lahan terdaftar yang paling sedikit diantara kecamatan lainnya di Kabupaten Semarang[4]. Hal tersebut berdampak pada sistem administrasi lahan dan perencanaan penataan ruang Kecamatan Sumowono yang dijadikan kawasan pertanian produktif melalui sistem agropolitan. Rendahnya jumlah bidang tanah yang telah terdaftar atau yang telah diberikan legalitas asetnya berpengaruh terhadap kepastian hukum atas ase tanah, baik bagi masyarakat, pemerintah dan dunia usaha [5]. Pada gilirannya hal tersebut dapat berdampak bagi kerentanan terjadinya sengketa dan konflik pertanahan di kawasan tersebut.

Kepastian legalitas aset tanah masyarakat dalam bentuk sertifikat hak atas tanah memiliki kontribusi dalam upaya peningkatan kesejahteraan masyarakat dengan dimanfaatkan sebagai sumber ekonomi masyarakat dalam rangka penguatan modal usaha [6]. Untuk meningkatkan sumber daya khususnya di bidang permodalan, diperlukan reforma agraria yakni asset reform dan akses reform. Asset reform berbicara mengenai program legalisasi aset, yaitu dengan pendaftaran tanah untuk mendapatkan jaminan kepastian hukum kepemilikan hak atas tanah, sedangkan akses reform diberikan pasca legalisasi asset melalui bantuan keuangan dari bank untuk mengembangkan kawasan pertanian. Properti akan diterima sebagai jaminan apabila dibuktikan dengan hak kepemilikan [7].

Legalitas aset tanah melalui sertifikat tanah secara potensial meningkatkan nilai tanah, memberikan rasa aman masyarakat terhadap asset tanahnya, dan meningkatkan terhadap akses masyarakat pada lembaga-lembaga keuangan. Hal ini berarti sertifikasi tanah meningkatkan kondisi sosial ekonomi serta kesejahteraan masyarakat pemilik tanah [8]. Oleh sebab itu percepatan legalisasi aset/ tanah merupakan sebuah strategi untuk mewujudkan pembangunan nasional di bidang pertanahan khususnya di Kecamatan Sumowono yang direncanakan sebagai kawasan pertanian produktif. Administrasi lahan di Sumowono dapat dilakukan dengan optimal apabila seluruh bidang tanah pada kawasan tersebut sudah terdaftar, sehingga perencanaan, pemanfaatan dan pengendalian kawasan tersebut dapat dilakukan secara seksama. Oleh sebab itu, diperlukan strategi yang tepat guna mengatasi permasalahan registrasi lahan. 
Pemerintah merencanakan program pendaftaran tanah secara sistematik, yaitu kegiatan pendaftaran tanah untuk pertama kali yang dilakukan secara serentak yang meliputi semua obyek pendaftaran tanah yang belum didaftar dalam wilayah atau bagian wilayah suatu desa/ kelurahan. Kegiatan pendaftaran tanah mengacu pada sistem dimana lembaga negara mencatat hak properti dan variasi pemegang tanah dalam buklet khusus sesuai dengan ketentuan hukum yang relevan dan prosedur tertentu untuk melindungi hak-hak pemegang tanah dan memfasilitasi pengelolaan lahan [9]. Sistem pendaftaran tanah yang merupakan program andalan pemerintah guna mengatasi permasalahan pendaftaran tanah dikenal dengan nama pendaftaran tanah sistematik lengkap (PTSL).

Tujuan dari penelitian ini adalah untuk menentukan prioritas lokasi pendaftaran tanah sistematik lengkap (PTSL) di Kecamatan Sumowono. Dengan ditentukannya prioritas lokasi PTSL pada tahap perencanaan, maka kegiatan tersebut akan berjalan dengan optimal karena semua stakeholder terkait seperti, pemerintah, masyarakat, dan swasta dapat bersinergi demi kelancaran kegiatan pendaftaran tanah.

\section{Metode}

\subsection{Gambaran umum lokasi studi}

Kecamatan Sumowono merupakan salah satu Kecamatan di Kabupaten Semarang. Wilayahnya terdiri dari 16 desa, yaitu Desa Kebonangung, Ngadikerso, Lanjan, Candigaron, Kemitir, Trayu, Sumowono, Jubelan, Bumen, Mendongan, Losari, Kemawi, Piyanggang, Pledokan, Duren, dan Keseneng. Peta administrasi Kecamatan Sumowono dapat dilihat pada Gambar 1.

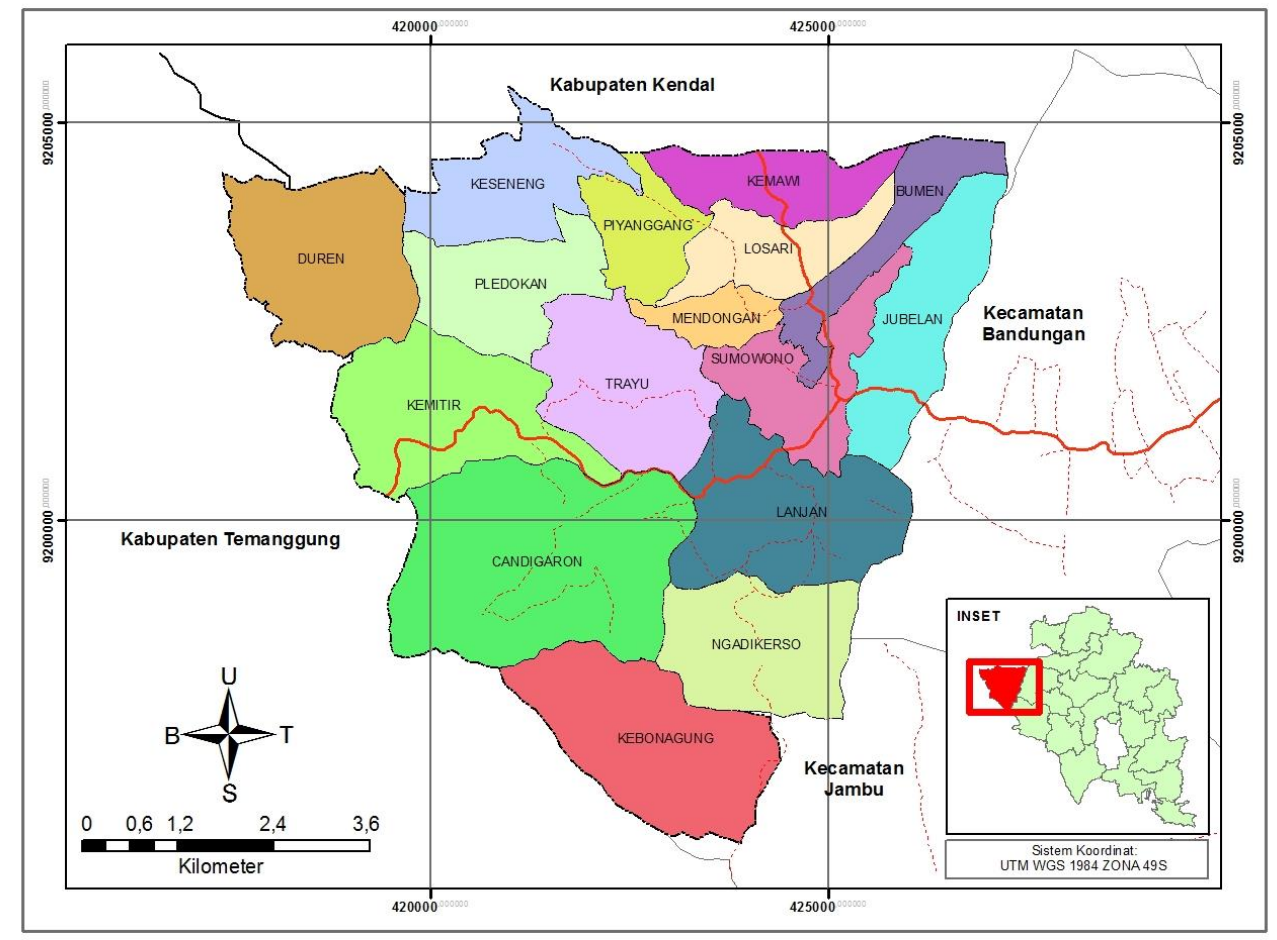

Gambar 1. Peta administrasi Kecamatan Sumowono. 
Sesuai dengan rencana tata ruang wilayah yang tertuang dalam Peraturan Daerah Kabupaten Semarang Nomor 6 Tahun 2011 tentang Rencana Tata Ruang Wilayah Kabupaten Semarang Tahun 2011 - 2031 [10], Kecamatan Sumowono direncanakan menjadi kawasan pertanian produktif, dengan sistem agropolitan. Penataan ruang kawasan agropolitan dapat dilakukan dengan optimal apabila seluruh bidang tanah pada kawasan tersebut sudah terdaftar, sehingga perencanaan, pemanfaatan dan pengendaliannya dapat dilakukan dengan seksama. Kendati demikian, Kecamatan Sumowono memiliki paling sedikit jumlah bidang tanah sudah terdaftar dibandingkan dengan kecamatan lainnnya, yakni sejumlah kurang lebih 14.361 bidang tanah [4]. Diperlukan strategi penentuan prioritas lokasi pendaftaran tanah, guna mempercepat kegiatan pendaftaran tanah.

\subsection{Sumber dan jenis data}

Dalam penelitian ini, data yang digunakan terdiri dari data primer dan data sekunder. Sumber data primer diperoleh dengan survei langsung di lapangan untuk memperoleh dan data jarak Kantor Desa ke Kantor Pertanahan Kabupaten Semarang, sedangkan data primer lainnya diperoleh dari wawancara dengan para narasumber, yaitu ahli pendaftaran tanah dari Kantor Pertanahan Kabupaten Semarang dan Kantor Wilayah Badan Pertanahan Provinsi Jawa Tengah. Sumber data sekunder diperoleh dari publikasi tahunan yang diterbitkan oleh Badan Pusat Stastistik Kabupaten Semarang [11]. Data sekunder yang digunakan adalah jumlah penduduk bekerja, kepadatan penduduk, panjang jalan, tingkat kelerengan, data jumlah bidang terdaftar, data luas lahan belum terdaftar, data luas penggunaan tanah.

\subsection{Metode analisa data}

Penelitian ini menggunakan metode campuran yaitu menggabungkan pendekatan kualitatif dan kuantitatif dalam penelitian. Kriteria dan subkriteria terbentuk berdasarkan studi literatur dan kajian-kajian empiris dari penelitian sebelumnya. Kriteria dan subkriteria yang sudah terbentuk digunakan sebagai dasar untuk mengumpulkan data. Penggunaan metode analisis hierarkhi proses (AHP) dan overlay tertimbang (weighted overlay) dinilai sangat tepat untuk untuk menentukan prioritas lokasi pendaftaran tanah.

2.3.1. Analisis Hierarki Proses (AHP).Analisis data dilakukan secara bertahap dengan cara memberikan bobot pada penilaian variabel yang digunakan dengan metode analytical hierarchy process (AHP). Proses dalam tahap AHP akan menghasilkan data kualitatif berupa pendapat para ahli tentang perbandingan tingkat kepentingan antar variabel yang digunakan dalam menentukan prioritas pendaftaran tanah. Sebelum melakukan AHP, perlu dilakukan penyusunan tujuan, kriteria dan sub kriteria penelitian ke dalam bentuk hirarki. Hirarki terbentuk dalam tiga tingkatan, yaitu tujuan pada tingkatan pertama, kriteria pada tingkatan kedua, dan subkriteria pada tingkatan ketiga. Susunan hirarki pada tahap AHP tampak pada Gambar 2. 


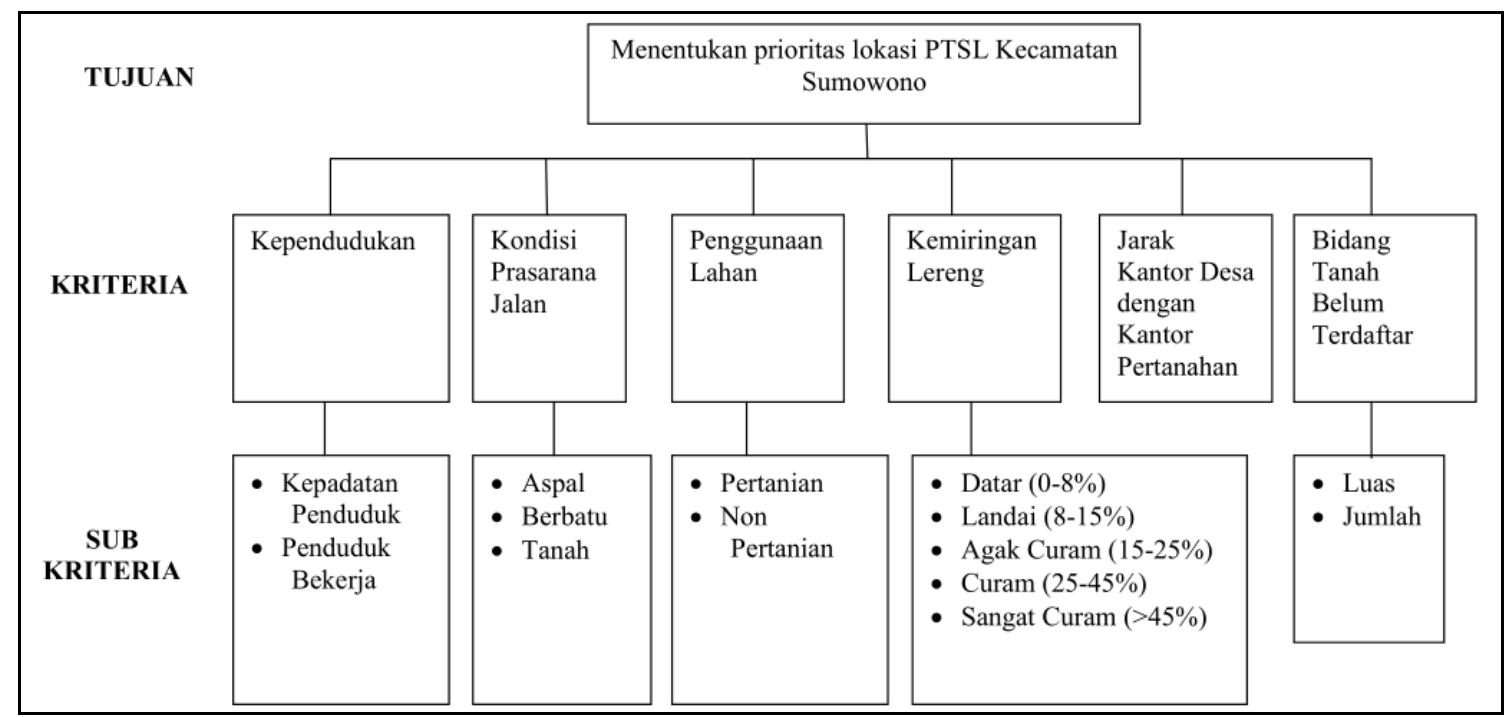

Gambar 2. Struktur hirarki AHP.

Proses selanjutnya adalah pembobotan tingkat kepentingan masing-masing kriteria dan subkriteria menggunakan matrik berpasangan. Perbandingan kepentingan antar kriteria dan subkriteria dinilai menggunakan skala 1-9 seperti terlihat dalam Gambar 3.

\begin{tabular}{|lll|}
\hline $\begin{array}{l}\text { Intensity of } \\
\text { Importance }\end{array}$ & \multicolumn{1}{c|}{ Definition } & \multicolumn{1}{c|}{ Explanation } \\
\hline 1 & $\begin{array}{l}\text { Equal Importance } \\
\text { Weak or slight } \\
\text { Moderate importance }\end{array}$ & $\begin{array}{l}\text { Two activities contribute equally to the objective } \\
\text { Experience and judgement slightly favour } \\
\text { one activity over another }\end{array}$ \\
4 & $\begin{array}{l}\text { Moderate plus } \\
\text { Strong importance }\end{array}$ & $\begin{array}{l}\text { Experience and judgement strongly favour } \\
\text { one activity over another }\end{array}$ \\
6 & $\begin{array}{l}\text { Strong plus } \\
\text { Very strong or } \\
\text { demonstrated importance }\end{array}$ & $\begin{array}{l}\text { An activity is favoured very strongly over } \\
\text { another; its dominance demonstrated in practice }\end{array}$ \\
8 & $\begin{array}{l}\text { Very, very strong } \\
\text { Extreme importance }\end{array}$ & $\begin{array}{l}\text { The evidence favouring one activity over another } \\
\text { is of the highest possible order of affirmation }\end{array}$ \\
\hline
\end{tabular}

Gambar 3. Skala ranking Saaty [12].

Langkah selanjutnya adalah menguji konsistensi nilai pada matrik berpasangan menggunakan kalkulator AHP. Dengan kalkulator AHP, hasil wawancara diinputkan sesuai dengan penilaian narasumber terhadap masing-masing variabel. Kalkulator AHP akan menghitung tingkat konsistensi jawaban atau rasio konsistensi jawaban para narasumber. Nilai rasio konsistensi tidak boleh lebih dari $10 \%$. Jika saat dihitung nilainya lebih dari $10 \%$, maka diperlukan pengulangan penilaian tingkat kepentingan variabel pada tahap wawancara. Tampilan kalkulator AHP saat digunakan untuk menghitung pembobotan masing-masing kriteria dan subkriteria dalam penelitian ini tampak seperti pada Gambar 4. 


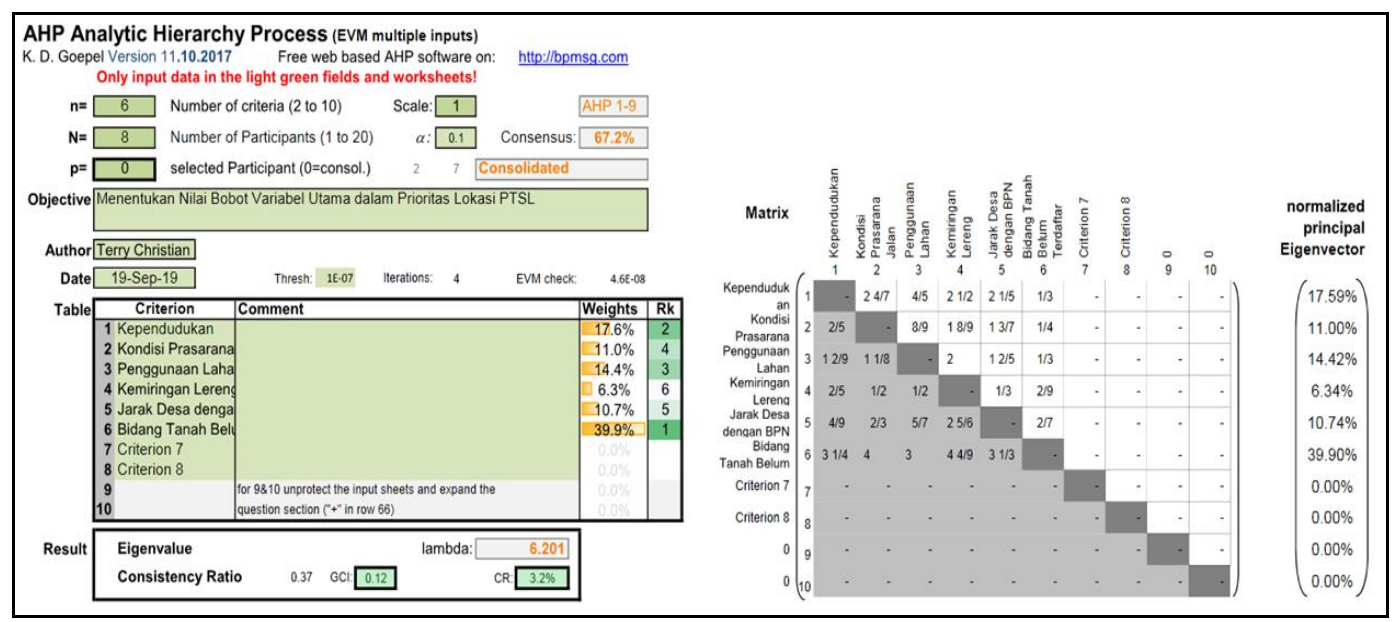

Gambar 4. Proses pembobotan dengan kalkulator AHP.

2.3.2. Analisis overlay tertimbang/ weighted overlay. Pada tahap ini, semua variabel terbentuk, diintegrasikan dengan data hasil observasi lapang maupun data sekunder yang ada. Pembuatan peta raster yang sudah direklasifikasi berdasarkan integrasi data sekunder yang diperoleh dari lapangan berupa nilai variabel masing-masing kriteria dan subkriteria menggunakan software ArcGIS 10.3. Integrasi data sekunder berupa data hasil pengukuran dilakukan dengan menginputkan data pada atribut pada peta Kecamatan Sumowono yang sudah dibagi dalam batas masing-masing desa. Pada langkah ini, akan dihasilkan data integrasi batas administratif desa dengan nilai variabel yang dimiliki masing-masing desa. Data berupa vektor diubah ke dalam bentuk raster menggunakan tool "polygon to raster" pada aplikasi ArcGIS 10.3. Data raster yang dihasilkan, kemudian diklasifikasi berdasarkan pembagian jumlah kelas sesuai kaidah sturges dan menghasilkan 5 klasifikasi. Proses reklasifikasi tampak pada Gambar 5.

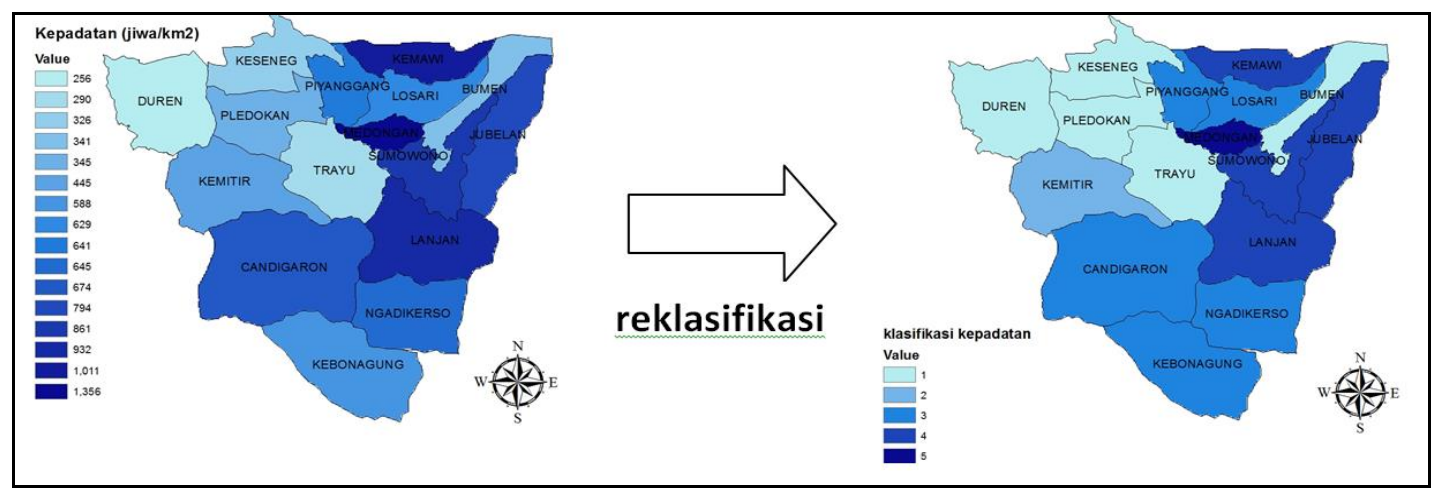

Gambar 5. Reklasifikasi raster.

Untuk menghasilkan peta prioritas, langkah terakhir menggunakan tool "weighted overlay" pada aplikasi ArcGIS 10.3. Dengan menginputkan hasil pembobotan pada tahapan AHP dengan raster yang sudah diklasifikasi akan diperoleh peta baru yang dikelompokkan menurut nilai nya. Semakin tinggi nilainya maka akan memiliki tingkatan prioritas yang lebih tinggi [13]. Gambar 6 menunjukkan skema proses analisis overlay tertimbang secara keseluruhan. 


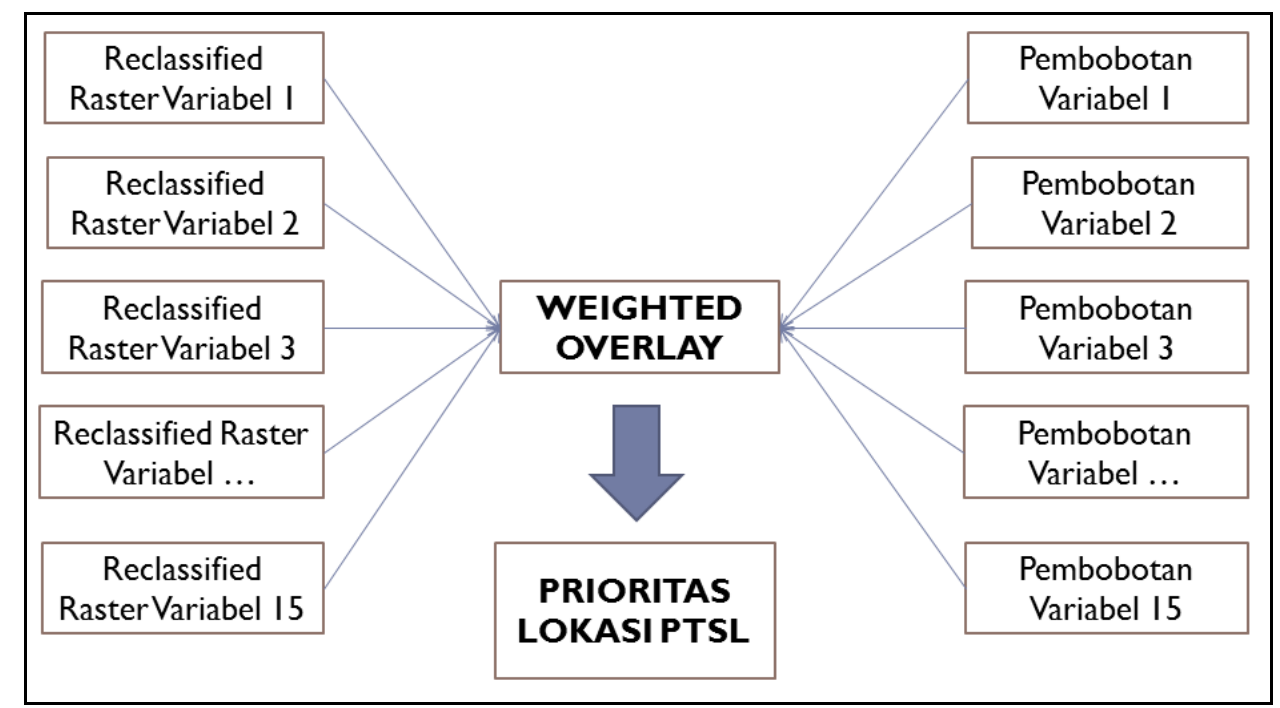

Gambar 6. Skema analisis overlay tertimbang.

\section{Hasil dan pembahasan}

\subsection{Pembobotan kriteria menggunakan AHP}

Pada tahap pembobotan ini, peneliti menggunakan metode purposive sampling dalam mengumpulkan informasi untuk pembobotan variabel. Narasumber berjumlah 8 orang yang merupakan pakar terkait bidang pendaftaran tanah, baik di bidang fisik maupun yuridis yang sudah berpengalaman melaksanakan pendaftaran tanah di berbagai tempat di seluruh Indonesia dengan pengalaman kerja dan bidang keahlian terkait pendaftaran tanah. Narasumber berasal dari Kantor Wilayah Badan Pertanahan Nasional Provinsi Jawa Tengah dan Kantor Pertanahan Kabupaten Semarang yang menjabat sebagai: (1) Kepala Seksi Infrastruktur Pertanahan, (2) Kepala SubSeksi Pengukuran Dasar, (3) Kepala Seksi Pendaftaran Hak Tanah, (4) Kepala Seksi Pengukuran dan Pemetaan Dasar, (5) Kepala Seksi Pengukuran dan Pemetaan Kadastral, (6) Kepala Seksi Survei dan Pemetaan dan Tematik, (7) Kepala Seksi Penetapan Hak Tanah dan Pemberdayaan Hak Tanah Masyarakat, dam (8) Kepala Seksi Pemeliharaan Data Hak Tanah dan Pembinaan PPAT.

Penggabungan pendapat ahli dari kedua instansi diharapkan akan memperoleh kajian yang obyektif sesuai keahlian mereka. Ahli yang berasal dari Kantor Pertanahan Kabupaten Semarang, memiliki pemahaman keruangan yang lebih spesifik. Sedangkan ahli yang berasal dari Kanwil BPN Provinsi Jawa Tengah memiliki pemahaman keruangan yang lebih luas, karena berada pada level koordinator.

Penentuan bobot kriteria dan subkriteria dilakukan dengan membandingkan tingkat kepentingan antar kriteria dan antar subkriteria berdasarkan hasil wawancara oleh para ahli. Nilai rasio konsistensi harus kurang dari atau sama dengan $10 \%$. Jika lebih dari $10 \%$, maka diperlukan pengulangan dalam penilaian tingkat kepentingan variabel. Hasil dari pembobotan kepentingan kriteria dapat dilihat pada Tabel 1. 
Tabel 1. Pembobotan kepentingan antar kriteria.

\begin{tabular}{|c|c|c|c|c|c|c|c|}
\hline \multirow[b]{2}{*}{$\begin{array}{l}\text { Nara- } \\
\text { sumber }\end{array}$} & \multicolumn{6}{|c|}{ Bobot Kriteria (\%) } & \multirow[t]{2}{*}{ CR (\%) } \\
\hline & $\begin{array}{c}\text { Kependu- } \\
\text { dukan }\end{array}$ & $\begin{array}{l}\text { Kondisi } \\
\text { Prasarana } \\
\text { Jalan }\end{array}$ & $\begin{array}{c}\text { Penggunaan } \\
\text { Lahan }\end{array}$ & $\begin{array}{c}\text { Kemiringan } \\
\text { Lereng }\end{array}$ & $\begin{array}{c}\text { Jarak Kantor } \\
\text { Desa dengan } \\
\text { Kantor } \\
\text { Pertanahan }\end{array}$ & $\begin{array}{l}\text { Bidang } \\
\text { Tanah } \\
\text { Belum } \\
\text { Terdaftar }\end{array}$ & \\
\hline 1 & 8 & 3 & 28 & 6 & 13 & 42 & 10 \\
\hline 2 & 29 & 9 & 34 & 4 & 5 & 20 & 10 \\
\hline 3 & 9 & 4 & 23 & 5 & 5 & 54 & 6 \\
\hline 4 & 3 & 26 & 5 & 12 & 16 & 37 & 8 \\
\hline 5 & 34 & 20 & 10 & 10 & 14 & 12 & 9 \\
\hline 6 & 24 & 9 & 5 & 2 & 7 & 52 & 10 \\
\hline 7 & 36 & 11 & 5 & 5 & 15 & 28 & 9 \\
\hline 8 & 9 & 9 & 16 & 4 & 4 & 57 & 9 \\
\hline TOTAL* & 17 & 11 & 14,4 & 6,3 & 10,7 & 39,9 & 3,2 \\
\hline
\end{tabular}

Keterangan:

* nilai total didapat dari normalized eigenvector

$\mathrm{CR}=$ Consistensi Ratio

Langkah yang sama dilakukan juga kepada masing-masing subkriteria untuk mendapatkan bobot masing-masing subkriteria. Setelah didapatkan bobot masing-masing subkriteria, kemudian diproporsikan ke dalam bobot kriteria sehingga didapatkan bobot akhir. Hasil akhir pembobotan pada tahap AHP ditunjukkan pada Tabel 2.

Tabel 2. Hasil akhir pembobotan kriteria dan subkriteria.

\begin{tabular}{clll}
\hline No & Kriteria Kependudukan (17,6\%) & \\
\hline \multirow{2}{*}{1} & Subkriteria & Bobot & Bobot Akhir \\
2 & Kepadatan Penduduk & $24,0 \%$ & $\mathbf{4 , 2 \%}$ \\
& Jumlah Penduduk Bekerja & $76,0 \%$ & $\mathbf{1 3 , 4 \%}$ \\
\cline { 2 - 3 } & Kriteria Prasarana Jalan (11,0\%) & \\
\cline { 2 - 4 } 3 & Subkriteria & Bobot & Bobot Akhir \\
4 & Jalan Aspal & $58,9 \%$ & $\mathbf{6 , 5 \%}$ \\
5 & Jalan Berbatu & $18,3 \%$ & $\mathbf{2 \%}$ \\
& Jalan Tanah & $22,7 \%$ & $\mathbf{2 , 5 \%}$ \\
\cline { 2 - 4 } & Kriteria Penggunaan Lahan (14,4\%) & \\
\cline { 2 - 4 } 6 & Subkriteria & Bobot & Bobot Akhir \\
7 & Pertanian & $41,8 \%$ & $\mathbf{6 \%}$ \\
& Non Pertanian & $58,1 \%$ & $\mathbf{8 , 4 \%}$ \\
\cline { 2 - 4 } 8 & Kriteria Kemiringan Lereng (6,3\%) & \\
\cline { 2 - 4 } 9 & Subkriteria & Bobot & $\mathbf{B o b o t ~ A k h i r ~}$ \\
10 & Landai & $39,2 \%$ & $\mathbf{2 , 5 \%}$ \\
11 & Curak Curam & $31,8 \%$ & $\mathbf{2 \%}$ \\
12 & Sangat Curam & $13,6 \%$ & $\mathbf{0 , 9 \%}$ \\
\hline
\end{tabular}

Received : October 28, 2019; Accepted: January 23, 2019; Available online: January 30, 2021 


\begin{tabular}{llll}
\hline No & \multicolumn{3}{l}{ Kriteria Jarak Desa dengan Kantor BPN (10,7\%) } \\
\cline { 2 - 4 } & Subkriteria & Bobot & Bobot Akhir \\
13 & - & - & $\mathbf{1 0 , 7 \%}$ \\
& & \\
\cline { 2 - 4 } & Tanah Belum Terdaftar (39,9\%) & \\
\cline { 2 - 4 } & Subkriteria & Bobot & Bobot Akhir \\
14 & Luas Lahan & $24,0 \%$ & $\mathbf{9 , 6 \%}$ \\
15 & Jumlah Bidang Tanah & $\mathbf{7 6 , 0 \%}$ & $\mathbf{3 0 , 3 \%}$ \\
\hline
\end{tabular}

Hasil akhir pembobotan menunjukkan bahwa variabel jumlah bidang tanah belum terdaftar mendapat bobot tertinggi, yaitu 30,3\%, variabel jumlah penduduk bekerja mendapat bobot $13,4 \%$, variabel jarak Kantor Desa dengan Kantor Pertanahan mendapat bobot $10,7 \%$, dan variabel luas bidang tanah belum terdaftar mendapat bobot $9,6 \%$. Untuk kriteria penggunaan lahan, variabel lahan non pertanian mendapatkan bobot $8,4 \%$.

Jumlah tanah terdaftar digunakan sebagai variabel penentu prioritas lokasi pendaftaran tanah dengan ketentuan bidang tanah terdaftar yang lebih sedikit, akan lebih diprioritaskan [14]. Hal ini dilakukan karena sifat dari pendaftaran tanah ini adalah sistematis. Marryanti dan Purbawa [15] juga mengungkapkan bahwa di semua desa/ kelurahan masih banyak terdapat bidang yang belum terdaftar, akan lebih menjadi prioritas untuk dilakukan pendaftaran tanah secara sistematis.

Jarak Kantor Desa ke Kantor Pertanahan dengan korelasi angka kepadatan penduduk dan luas penggunaan tanah menurut Setyawan [16] berpengaruh signifikan dalam penentuan prioritas lokasi pendaftaran tanah. Kebutuhan akses informasi dan mobilitas menjadi salah satu syarat dalam penentuan prioritas lokasi prona. Semakin dekat jarak Kantor Desa lokasi PTSL dengan Kantor Pertanahan, maka akan semakin mudah pelaksanaan kegiatannya. Hal tersebut terjadi karena kegiatan PTSL memerlukan koordinasi antar tim untuk menyelesaikan permasalahan yang ada di lapangan.

Kriteria yang berpengaruh signifikan terhadap penentuan prioritas lokasi prona adalah perbandingan luas penggunaan tanah [16]. Penggunaan tanah yang dimaksud dikategorikan menjadi 2, yaitu pertanian dan non pertanian. Untuk mendukung percepatan pelaksanaan pengukuran dan pendaftaran tanah secara sitematik, lahan non pertanian mendapatkan bobot lebih tinggi daripada lahan pertanian. Hal tersebut dikarenakan lahan non pertanian memiliki luas bidang tanah yang lebih kecil dibandingkan dengan lahan pertanian, sehingga dalam waktu yang sama akan didapatkan jumlah bidang terdaftar lebih banyak.

Kemiringan lereng menjadi salah satu faktor penentu keberhasilan PTSL. Penelitian Marryanti \& Purbawa [15], mengungkapkan bahwa pada kemiringan lereng $<3 \%$ akan mempermudah pelaksanaan PTSL. Pada variabel ini, kemiringan lereng dibagi menjadi lima kelompok, yaitu datar, landai, agak curam, curam, dan sangat curam. Kemiringan lereng pada sub-kriteria datar mendapat bobot tertinggi dari kriteria kemiringan lereng, yakni 2,5\%. 


\subsection{Prioritas lokasi pendaftaran tanah sistematik lengkap}

Penentuan prioritas lokasi pendaftaran tanah sistematik lengkap menggunakan dua masukan/ input utama, yaitu nilai bobot masing-masing variabel dan nilai raster yang sudah diklasifikasi. Pada tampilan tool weighted overlay, masing-masing variabel memiliki tingkat pengaruh dalam penentuan prioritas lokasi PTSL. Besarnya pengaruh tersebut akan dipadukan dengan nilai hasil klasifikasi sesuai dengan besaran nilai riil masing-masing variabel per desa. Metode weighted overlay adalah analisis spasial menggunakan beberapa teknik overlay peta terkait faktor-faktor yang mempengaruhi penilaian obyek berupa lahan/ hamparan. Teknik overlay peta digunakan untuk analisis overlay tertimbang (weighted overlay) yang diintegrasikan dengan analisis multi-kriteria [17]. Penggunaan metode ini menggunakan data raster yang diberi skor dan pembobotan pada setiap pikselnya. Dengan demikian, setiap piksel pada raster tersebut mempunyai nilainya masing-masing [18]. Nilai masing-masing raster akan mempengaruhi hasil akhir mempertimbangkan bobot setiap variabelnya.

Semua input pada penggunaan tool weighted overlay harus berupa bilangan bulat seperti tampak pada Gambar 7. Poligon yang berisi data atribut harus dikonversi menjadi raster sebelum digunakan dalam overlay tertimbang. Raster tersebut kemudian diklasifikasikan ke dalam 5 kelas menurut rumus sturges dan diberi nilai baru berdasarkan skala evaluasi. Setiap raster yang sudah diklasifikasikan diberi bobot sesuai dengan hasil akhir pembobotan pada tahap AHP. Analisis weighted overlay menghasilkan data raster yang memiliki nilai berupa penjumlahan skor masing-masing variabel sesuai dengan bobot klasifikasinya. Hasil proses weighted overlay berupa prioritas lokasi PTSL dapat dilihat pada Gambar 7.

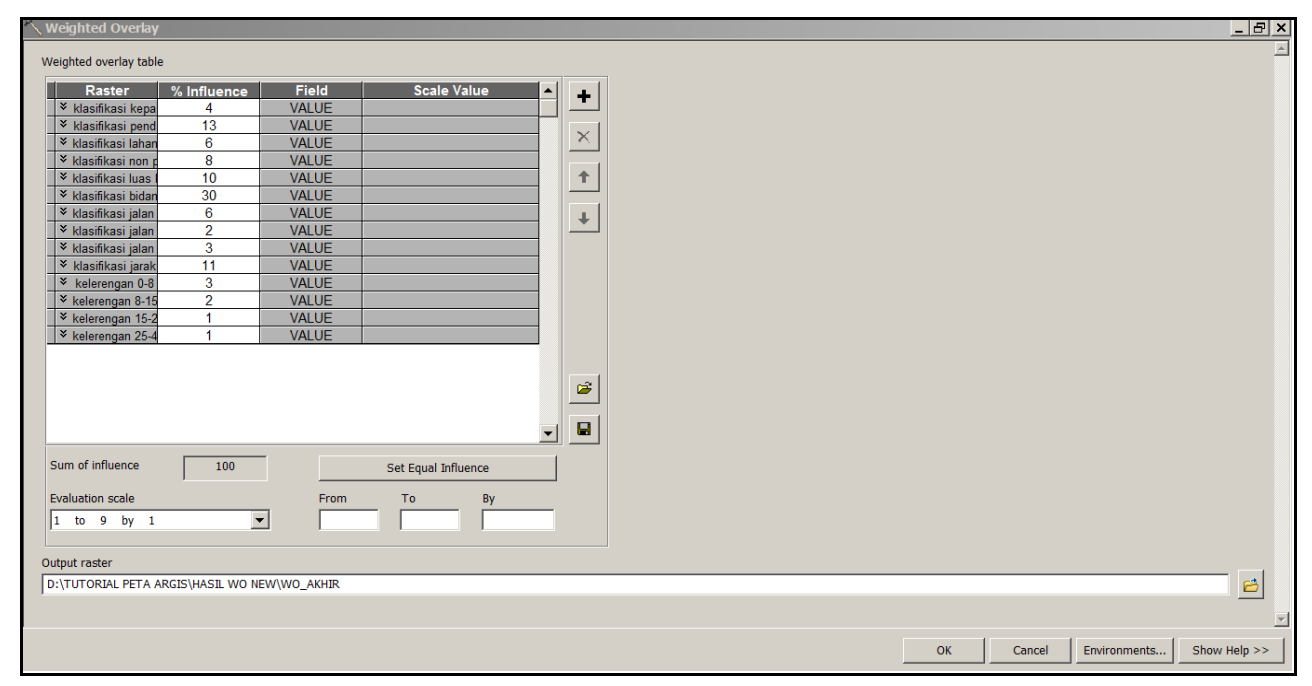

Gambar 7. Jendela tool weighted overlay Arc GIS 10.3.

Berdasarkan hasil analisis weighted overlay, terdapat 3 tingkatan prioritas dalam penentuan lokasi pendaftaran tanah sistematik lengkap (PTSL). Prioritas pertama terdiri dari 1 desa yang ditandai dengan warna biru. Prioritas kedua terdiri dari 9 desa yang ditandai dengan warna kuning, yaitu desa dan prioritas ketiga terdiri dari 6 desa yang ditandai dengan warna hijau. 


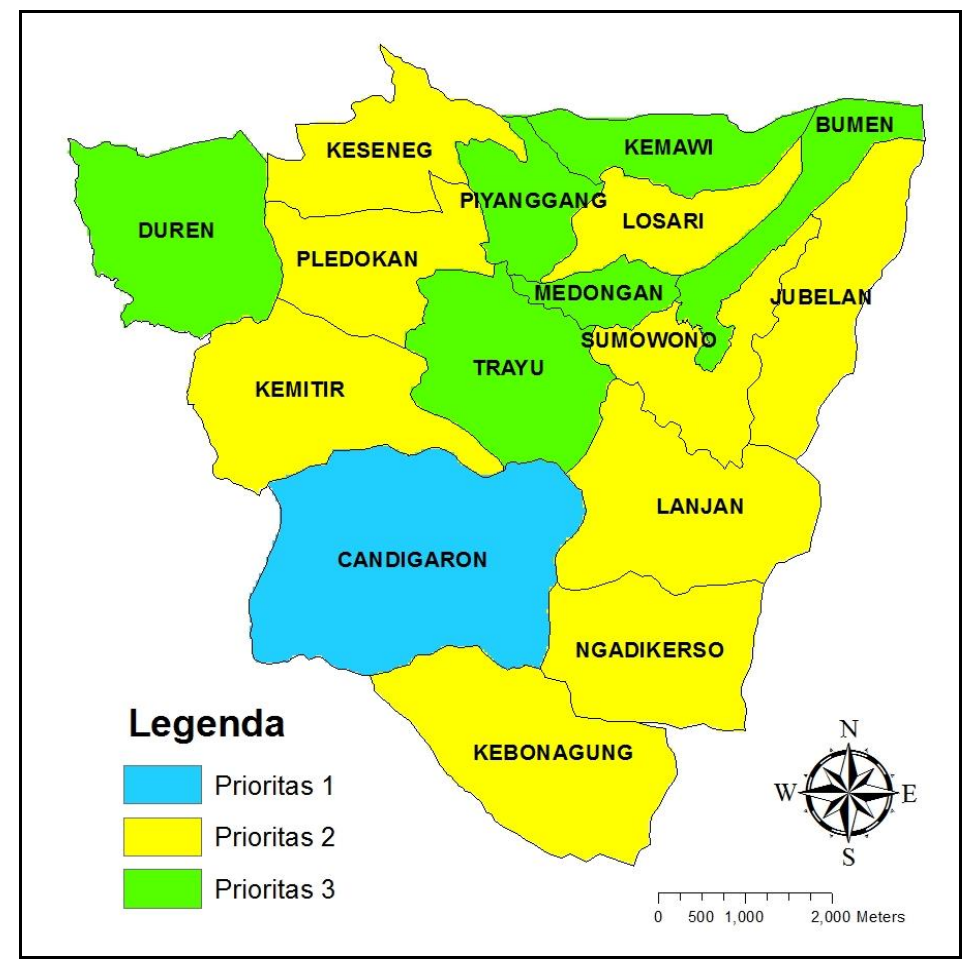

Gambar 8. Prioritas lokasi PTSL Kecamatan Sumowono.

Prioritas pertama hanya terdapat di Desa Candigaron. Ditinjau dari aspek jumlah bidang tanah belum terdaftarnya yang merupakan bobot tertinggi menurut para ahli (30\%), desa ini diperkirakan memiliki kurang lebih 4.449 bidang tanah dengan luas $5.926 .161 \mathrm{~m}^{2}$. Jumlah tersebut merupakan nilai tertinggi dibandingkan dengan desa lainnya. Jumlah penduduk bekerja di desa ini juga menempati posisi tertinggi, yaitu sejumlah 3.378 orang dengan bobot variabel sebesar $13 \%$ menurut para ahli. Dilihat dari aspek fisiknya, Desa Candigaron mempunya luas lahan pertanian non sawah seluas $6.055 .700 \mathrm{~m}^{2}$, panjang jalan aspal sejauh $10 \mathrm{~km}$, dan sebagian besar wilayahnya memiliki kelerengan $15-25 \%$ seluas $7.159 .600 \mathrm{~m}^{2}$. Namun jika dilihat dari kepadatan penduduknya, Desa Candigaron menempati urutan keenam terpadat di Kecamatan Sumowono dengan kepadatan mencapai $674 \mathrm{jiwa} / \mathrm{km}^{2}$.

Prioritas kedua terdiri dari 9 desa, yakni Desa Keseneg, Desa Pledokan, Desa Kemitir, Desa Losari, Desa Sumowono, Desa Jubelan, Desa Lanjan, Desa Ngadikerso dan Desa Kebonagung. Kesembilan desa tersebut rata-rata memiliki jumlah bidang terdaftar sebanyak 1.085 bidang, dan sebanyak 1.926 bidang belum terdaftar dengan luasan $2.541 .544 \mathrm{~m}^{2}$ yang tersebar di kelerengan $0-8 \%$ sebanyak $20 \%$, $8-15 \%$ sebanyak $3 \%$, $15-25 \%$ sebanyak $74 \%$, dan $25-40 \%$ sebanyak $4 \%$ dari luas wilayahnya. Jumlah penduduk bekerja rata-rata adalah 1.536 jiwa dengan kepadatan penduduk rata-rata mencapai $618 \mathrm{jiwa} / \mathrm{km}^{2}$. Sebagian besar penggunaan tanah dari sembilan desa tersebut adalah tanah pertanian seluas $27.658 .100 \mathrm{~m}^{2}$ yang terbagi menjadi dua kategori, yakni tanah pertanian sawah seluas 4.678 .400 dan pertanian non sawah $22.979 .700 \mathrm{~m}^{2}$. Untuk tanah non pertanian memiliki luas total $8.029 .500 \mathrm{~m}^{2}$. Kondisi prasarana jalan kesembilan desa ini memiliki jalan aspal sepanjang $67,68 \mathrm{~km}$, jalan berbatu sepanjang $10,97 \mathrm{~km}$, dan jalan tanah sepanjang $10,25 \mathrm{~km}$. Jarak tempuh rata-rata dari Kantor Pertanahan Kabupaten Semarang menuju Kantor Kepala Desa setempat adalah 26,8km.

Received: October 28, 2019; Accepted: January 23, 2019; Available online: January 30, 2021 152 Copy right $\odot$ 2021, REGION: Jurnal Pembangunan Wilay ah dan Perencanaan Partisipatif 
Prioritas ketiga terdiri dari enam desa, yaitu Desa Medongan, Desa Kemawi, Desa Piyanggang, Desa Bumen, Desa Trayu, dan Desa Duren. Keenam desa tersebut memiliki jumlah belum terdaftar kurang lebih 752 bidang dengan luas $1.285 .534 \mathrm{~m}^{2}$. Bidang tanah belum terdaftar tersebar di kelerengan $0-8 \%$ sebanyak $20 \%, 15-25 \%$ sebanyak $48 \%$ dan 25 $40 \%$ sebanyak $30 \%$. Jumlah penduduk bekerja rata-rata di keenam desa ini hanya sebanyak 667 jiwa dengan kepadatan penduduk $649 \mathrm{jiwa} / \mathrm{km}^{2}$. Jarak tempuh rata-rata dari Kantor Pertanahan Kabupaten Semarang menuju Kantor Kepala Desa setempat adalah 27,2km.

\section{Kesimpulan}

Penataan ruang Kecamatan Sumowono yang direncanakan menjadi kawasan pertanian produktif melalui sistem agropolitan perlu didukung dengan percepatan pendaftaran tanah. Program pendaftaran tanah sistematik lengkap (PTSL) memerlukan strategi khusus yakni dengan perencanaan kegiatan pendaftaran berupa penentuan prioritas lokasi Pendaftaran Tanah Sistematik Lengkap (PTSL). Dalam penentuan prioritas lokasi PTSL, tidak hanya dilihat dari jumlah bidang dan luas bidang tanah yang belum terdaftar saja, namun mempertimbangkan kriteria lain, seperti aspek kependudukan, kondisi prasarana jalan, jarak, penggunan lahan, dan aspek fisik lainnya seperti kelerengan. Integrasi hasil pembobotan oleh para ahli dan data sekunder yang ada ke dalam sistem informasi spasial, menghasilkan prioritas lokasi PTSL di Kecamatan Sumowono.

Hasil analisis berupa prioritas lokasi PTSL di Kecamatan Sumowono dapat digunakan sebagai alat bantu bagi pemangku kebijakan dalam percepatan pendaftaran tanah di Kabupaten Semarang. Berdasarkan hasil analisis, Desa Candigaron menempati prioritas pertama dalam program PTSL; kemudian 9 desa lainnya yaitu Desa Keseneg, Desa Pledokan, Desa Kemitir, Desa Losari, Desa Sumowono, Desa Jubelan, Desa Lanjan, Desa Ngadikerso dan Desa Kebonagung menempati prioritas kedua; dan 6 desa terakhir, yaitu Desa Medongan, Desa Kemawi, Desa Piyanggang, Desa Bumen, Desa Trayu, dan Desa Duren menempati prioritas ketiga.

\section{Ucapan Terimakasih}

Terima kasih kepada pihak yang telah membantu penulisan dalam penelitian ini, khususnya Kementerian Perencanaan Pembangunan Nasional/ BAPPENAS atas dukungan pembiayaan yang diberikan selama menjalani masa studi di Universitas Diponegoro, kepada Kantor Pertanahan Kabupaten Semarang yang telah membantu dalam pengumpulan data-data penelitian, serta kepada Jurnal REGION Universitas Sebelas Maret (UNS) yang telah memberi ruang dan kesempatan untuk mempublikasikan hasil penelitian ini supaya dapat bermanfaat bagi masyarakat pada umumnya dan peneliti-peneliti lainnya pada khususnya.

\section{Referensi}

[1] Williamson I P, Enemark S, Wallace J dan Rajabifard A 2010 Land Administration For Sustainable Development Proceedings of FIG Congress 2010 Facing the Challenges Building the Capacity Sydney, Australia pp 1-16 Diakses dari https://www.researchgate.net/publication/242494736_Land_Administration_for_S ustainable_Development

[2] Enemark S 2004 Building Land Information Policies Proceedings of Special Forum on

Received : October 28, 2019; Accepted: January 23, 2019; Available online: January 30, 2021

Copy right $\odot$ 2021, REGION: Jurnal Pembangunan Wilay ah dan Perencanaan Partisipatif 
Building Land Information Policies in the Americas pp 1-20 Diakses dari https://www.fig.net/resources/proceedings/2004/mexico/papers_eng/ts2_enemar k_eng.pdf

[3] Zaim Z, Buchori I dan Rudiarto I 2019 Land Tenure System and Utilization of Bengkok Land in Indrokilo sub-village, Lerep Village, Semarang Regency AIP Conference Proceedings 2114040010 DOI: 10.1063/1.5112439

[4] BPN Kabupaten Semarang 2019 Data Bidang Tanah Terdaftar Tiap Kecamatan di Kabupaten Semarang

[5] Abdulai R T dan Ochieng E 2017 Land Registration and Landownership Security Property Management 351 pp 24-47 DOI: 10.1108/PM-09-2015-0051

[6] Mulyani L, Yogaswara H, Masnum L dan Mardiana R 2011 Strategi Pembaruan Agraria Untuk Mengurangi Kemiskinan (Jakarta: Lembaga IImu Pengetahuan Indonesia) Diakses

dari https://www.researchgate.net/publication/263619358_Strategi_Pembaruan_Agrari a_untuk_Mengurangi_Kemiskinan_Latar_Belakang_Konsep_dan_Implementasi_Pro gram_PPAN

[7] Abdulai R T dan Hammond F N 2010 Landed Property Market Information Management And Access To Finance Property Management 284 pp 228-44 DOI: 10.1108/02637471011065665

[8] Mardiana Y S, Siregar H dan Juanda B 2016 Pengaruh Sertifikasi Tanah Terhadap Nilai Tanah Dan Kondisi Ekonomi Masyarakat Di Kabupaten Sukoharjo Jurnal Aplikasi Bisnis dan Manajemen 23 pp 304-11 DOI: 10.17358/JABM.2.3.304

[9] Lian H dan Yu Y 2016 Reference of Land Registration System from Countries in AsiaPacific Region: Comparison of the United States, Canada, Russia, South Korea, Japan and Australia IOSR Journal of Business and Management $187 \mathrm{pp}$ 31-40 DOI: 10.9790/487X-1807043140

[10] Peraturan Daerah Kabupaten Semarang Nomor 6 Tahun 2011 tentang Rencana Tata Ruang Wilayah Kabupaten Semarang Tahun 2011-2031 Diakses dari http://perpustakaan.bappenas.go.id/Iontar/file?file=digital/131218-[_Konten_]Konten\%20C9276.pdf

[11] Badan Pusat Statistik Kabupaten Semarang 2018 Kecamatan Sumowono Dalam Angka Tahun 2018 Katalog no. 1102001.3322090 Diakses dari https://semarangkab.bps.go.id/publication/2019/09/26/05f35935f440f09c6e86aac 7/kecamatan-sumowono-dalam-angka-2019.html

[12] Saaty T L 2008 Decision making with the analitic hiererchy process International Journal Services Sciences $1 \quad 1 \quad$ pp $83-98$ Diakses dari http://www.rafikulislam.com/uploads/resourses/197245512559a37aadea6d.pdf

[13] Arnold G, Carlock B, Harris M, Romney A, Rosa M, Zollweg J, Vodacek A, dan Tomaszweski B 2012 Modeling Social Vulnerability In Burkina Faso Focus, winter 2012 edition $p$ pp 20-23 Diakses dari https://www.esri.com/news/arcuser/0112/modeling-social-vulnerability-in-burkinafaso.html

[14] Hendriono D, Nugroho P dan Yulaikhah 2010 Penggunaan analytical hierarchy process untuk menentukan prioritas syarat lokasi pendaftaran tanah sistematik ajudikasi 
LMPDP (Studi kasus di Kabupaten Kulon Progo, D.I. Yogyakarta) Prosiding, Forum IImiah Tahunan 2010 Ikatan Surveyor Indonesia chapter J pp J1-J16 Diakses dari https://repository.ugm.ac.id/136671/1/MU_Dody\%20Hendriono\%20dkk.pdf

[15] Marryanti S dan Purbawa Y 2018 Optimalisasi Faktor-Faktor Yang Memengaruhi Keberhasilan Pendaftaran Tanah Sistematis Lengkap BHUMI: Jurnal Agraria Dan Pertanahan 42 pp 190-207 DOI: 10.31292/jb.v4i2.278

[16] Setyawan N 2008 Penentuan Prioritas Lokasi Prona Menggunakan Metode Rank Sum (Studi Kasus Kecamatan Purwanegara Kabupaten Banjarnegara Provinsi Jawa Tengah) Tesis (Bandung: Institut Teknologi Bandung) Diakses dari https://docplayer.info/46844969-Penentuan-prioritas-lokasi-prona-menggunakanmetode-rank-sum-studi-kasus-kecamatan-purwanegara-kabupaten-banjarnegaraprovinsi-jawa-tengah-tesis.html

[17] Chaudari R, Lal D, Dutta S, Umrikar B dan Halder S 2018 Weighted Overlay Analysis For Delineation Of Ground Water Potential Zone: A Case Study Of Pirangut River Basin International Journal of Remote Sensing \& Geoscience (IJRSG) 71 pp 1-7 Diakses dari

https://www.researchgate.net/publication/322757481_WEIGHTED_OVERLAY_ANA LYSIS_FOR_DELINEATION_OF_GROUND_WATER_POTENTIAL_ZONE_A_CASE_STUDY _OF_PIRANGUT_RIVER_BASIN

[18] Christiawan, S Jimmy dan Basuki, Yudi 2019 Penentuan Prioritas Peningkatan Pelayanan Penerangan Jalan Di Kota Kediri Jurnal Pembangunan Wilayah dan Kota Universitas Diponegoro 151 pp 34-46 DOI: 10.14710/pwk.v15i1.21066 